taria, et un degré plus faible dans les Daphne Cneorum, D. Altaica, \&c.

Alston "Materia Medica." This author mentions three of the Thymelacer in the following order :-1, Laureola; 2, Mezereon ; 3, Thymelæa. He says, "they are all of a burning hot taste, \&c. \&c.

"The berries are violent, and dangerous cathartics; every part of these plants is as bad as the berries." I shall make no further remarks on the subject but to say, that I have not bunted up rare books to find authorities, but have just opened a few that I happened to have in my small library, and $I$ now submit what I have written to the candid consideration of Dr. Sigmond and your readers. I am, Sir, yours respectfully,

London, June 27, 1840. JosePH Houlton.

\section{INQUEST AT ST. BARTHOLOMEW'S HOSPITAL.}

To the Editor of THE LANCET.

Sir :-The Lancet of May 30 contains a letter by a Juror at an inquest, held at St. Bartholomew's Hospital, on the body of John Ryan. Having been present at the inquest, $I$ am induced to make the following statement:- John Ryan, by the mother's evidence, was four year's old, and was attended by Dr. Arthur Farre, and Mr. Dodd, the general practitioner alluded to in the Juror's letter. Mr. Dodd, in my opinion, was not loath to inculpate the medical officers of the institution, as he at once said that the child, when he saw it, was salivated. Dr. Arthur Farre's evidence went to prove, that he ordered half a drachm of jalap and calomel, a preparation kept at the Dispensary (the quantity of calomel contained in half a scruple of this preparation is two grains, the remainder jalap), and that he intended it should be divided into three powders, one to be given to John Ryan, one to his brother or sister, and the other to John Ryan, at a stated time; therefore, there were only four grains of calomel ordered for him. The Juror seems inclined to blame the Coroner, saying he was either unable or unwilling to detect what was wrong, taking care not to inculpate himself or any of the other Jurors. He says that they recorded a verdict, "That the prescription was neglectfully compounded and that the child died from an overdose of mercury." This was delivered in as their verdict, and before it was recorded the Coroner asked them whether he understood them aright. Did they mean to inculpate any of the medical gentlemen? The reply was, unanimous, "Certainly not." The Coroner, also, during the inquiry, asked if the surgeon of the hospital, who attended the child, was there, and did the Jury think it necessary to have his evidence? The Jury expressed no wish to that effect, and the surgeon did not attend. If blame be attached to any one, it is to the Jury, and not to the Coroner, more especially to the Juror who finds fault. I am, Sir, your obedient servant,

\section{Mold, Flintshire, June 9, 1840.}

Robert Parry.

** Whether our correspondent means that the Jury were to blame, if culpable, for their " Certainly not," or the absence of the surgeon, is not clear; but we must remark, that no anonymous remarks on the questions at issue can have room found for them in our pages.

\section{UNPROFESSIONAL CONDUCT.}

Mr. William Henry Smith, of 5, Marl. borough-place, Walworth, surgeon, applied by letter to Mr. Matthias Rowe, of $\mathbf{2 4}$, Woburn-place, Russell-square, surgeon, on the 15th of June last, for an explanation of his proceeding in the following transactions, as described in a statement sent to us by $\mathrm{Mr}$. Smirn :- "About the middle of May last," says Mr. S., "I attended Mrs. L., of Walworth, in ber accouchement. Ten days after delivery, in consequence of her inability to suckle her infant, the breasts became inflamed, and, despite usual antiphlogistic treatment, suppurated. I proposed, at the proper stage, to open the abscesses, but the patient, who had twice before suffered from the same cause, strongly objected, and preferred waiting for the spontaneous discharge of the pus.

I attended her assiduously, seeing her twice daily, although she was otherwise doing well, and had visited her at eleven, A.M., on Sunday, June 14, when, on returning home from paying some visits, I found that a message had been left at my house from the patient, requesting me to call. I immediately went to her, and, to my astonishment, was informed that a Mr. Rowe had visited her, opened an abscess, and written a prescription, without having referred to me. This gentleman, $I$ was informed, had been sent to the patient by a friend of Mrs. L., whom he was attending, in the neighbourhood, and not by the request of Mrs. L. Deeming this conduct on the part of Mr. Rowe somewhat extraordinary, Mr. Smith wrote to Mr. Rowe as follows, having previously called upon him for an explanation, without finding the intruder at home :-

"Marlborough-place, June 15.

"SIR :-Upon paying a second visit to my patient, Mrs. L., of Walworth, I was greatly surprised to hear, that you, a perfect stranger to me, had, during my absence, visited her, and opened an abscess in her breast, and likewise had written a prescription for me to prepare. I had myself two or three times 